\title{
Budgetary impact analysis on funding smoking- cessation drugs in patients with COPD in Spain
}

\author{
This article was published in the following Dove Press journal: \\ International Journal of COPD \\ 24 September 2015 \\ Number of times this article has been viewed
}

\author{
Carlos A Jiménez-Ruiz' \\ Segismundo Solano-Reina ${ }^{2}$ \\ Jaime Signes-Costa ${ }^{3}$ \\ Eva de Higes-Martinez ${ }^{4}$ \\ José I Granda-Orive ${ }^{5}$ \\ José J Lorza-Blasco 6 \\ Juan A Riesco-Miranda ${ }^{7}$ \\ Neus Altet-Gomez ${ }^{8}$ \\ Miguel Barrueco 9 \\ Itziar Oyagüez ${ }^{10}$ \\ Javier Rejas"l
}

\section{On behalf of the SEPAR's Integrated Tobacco Research Program}

'Specialised Tobacco Unit, Community of Madrid, ${ }^{2}$ Tobacco Unit, Department of Pulmonary Medicine, Hospital General Universitario Gregorio Marañón, Madrid, ${ }^{3}$ Department of Pulmonary Medicine, Hospital Universitario San Juan, Alicante, ${ }^{4}$ Department of Pulmonary Medicine, Hospital Universitario Fundación Alcorcón, ${ }^{5}$ Department of Pulmonary Medicine, Hospital Universitario 12 de Octubre, Madrid, ${ }^{6}$ Department of Pulmonary Medicine, Complejo Hospitalario de Navarra, Pamplona, Navarre, ${ }^{7}$ Department of Pulmonary Medicine, Hospital de San Pedro Alcántara, Cáceres, ${ }^{8}$ Drassanes Tobacco Unit, Hospital Universitari Vall-d'Hebron-Drassanes, The Jordi Gol University Institute for Research Primary Healthcare, Barcelona, ${ }^{9}$ Department of Pulmonary Medicine, Hospital Universitario de Salamanca, Biomedical Research Institute, Salamanca, ${ }^{10}$ Pharmacoeconomics \& Outcomes Research Iberia, "Department of Pharmacoeconomics and Health Outcomes Research, Pfizer, Sociedad Limitada Unificada, Alcobendas, Madrid, Spain

Correspondence: Carlos A Jiménez-Ruiz Specialized Tobacco Unit, Sub-directorate for Health Promotion and Disease Prevention, Directorate-General for Primary Care, Consejería de Sanidad, C/Santa Cruz de Marcenado, 9-2, 28015 Madrid, Spain Tel +34 9l 2052960

Fax +34 9l 2044972

Email victorina@ctv.es

\begin{abstract}
The aim of the study was to assess the budgetary impact of funding smoking-cessation drugs in COPD patients in Spain. A hybrid model (cohort and Markov) was developed for a 5-year time horizon. Only approved cessation drugs (varenicline, bupropion, and nicotine replacement therapy) were considered. Irrespective of the drug, the model allowed for an initial cessation attempt, and up to three additional attempts in case of failure or smoking relapse during a 5-year period. Drug effectiveness was based on controlled clinical trials. National Health System perspective was applied; therefore, only medical resources were included. The pharmaceutical costs for smoking-cessation drugs, extra medical follow-up as a consequence of public reimbursement, and annual savings for health costs avoided due to stopping smoking were considered. The model estimated that 17,756 COPD patients would stop smoking if public funding was available, compared with 1,303 without reimbursement. In the reimbursement scenario, the savings accounted for a total of $€ 48.0$ million, compensating for expenditures on drugs and medical visits (€40.4 million). Accumulated total additional savings in 5 years (€4.3 million) compared with the scenario without reimbursement was shown. Sensitivity analyses supported the results robustness. Funding smoking-cessation drugs in COPD patients seems to be an efficient option and a National Health System drug reimbursement scheme would represent a cost-saving policy in Spain.
\end{abstract}

Keywords: pharmacotherapy, COPD, smoking cessation, budgetary impact, health service

\section{Introduction}

According to the World Health Organization, tobacco is the only legal product that causes death in half of those who consume it regularly. As such, of the worldwide 1.3 billion current smokers, 650 million are expected to die prematurely during the upcoming years, a number which represents $10 \%$ of the world's current population. ${ }^{1}$ Although the gradual implementation of educational measures and the banning of smoking in the public domain have led to a drop in the prevalence of smoking and its mortality, $>50,000$ people still die from its complications in Spain annually. Thus, a decrease in prevalence continues to be a primary objective for both clinicians and health authorities. ${ }^{2}$

There is scientific evidence that combining psychological counseling with drug treatment is the most effective and safe option for helping smokers quit smoking. ${ }^{3}$ Nicotine replacement therapy (NRT), bupropion, and varenicline are all recommended pharmacotherapies ${ }^{3}$ because they have been shown to be effective in smoking cessation in subjects with respiratory diseases, ${ }^{4,5}$ and some of them, like varenicline, have even been shown to be cost-effective in patients with COPD. ${ }^{6}$

Smoking cessation is a medical objective in patients with an elevated risk of developing smoking-related health problems or who already have them, as is the case with COPD. ${ }^{5,7,8}$ Moreover, smoking cessation in these patients has been shown to be 
associated with substantial savings for the Spanish National Health System (NHS), particularly in the health care-related component of costs, which are currently financed with public funds. ${ }^{9-11}$

Therefore, the aim of this study was to estimate the economic impact for the Spanish NHS budget where the currently approved drugs (varenicline, bupropion, and NRT) would be funded for the purposes of smoking cessation in patients with COPD.

\section{Methods}

\section{Design of the model}

According to national ${ }^{12}$ and international ${ }^{13}$ recommendations for developing budget-impact analyses (BIA), a decision analysis model was developed using Microsoft Excel 2007 to project, over a 5-year period, the cost of smoking cessation with psychological counseling plus smoking-cessation drugs in smokers with COPD in Spain. The BIA was performed using a hybrid model (cohort and Markov), which, from an epidemiological perspective, represents the population of patients with COPD who would try quitting smoking by using pharmacological aids additionally to counseling. The impact was estimated by comparing the cost of smoking cessation under public funding for the drugs evaluated, compared with the current situation, where these therapies are not funded by the NHS.

\section{Alternatives evaluated}

The therapies included are the three alternatives currently approved in Spain for smoking cessation: varenicline, bupropion, and NRT. Percentage distribution of use of each drug in the unfunded scenario corresponds to the figures seen in routine medical practice in Spain: ${ }^{14} 21.9 \%$ for varenicline, $25.1 \%$ for bupropion, and $53.0 \%$ for NRT. The distribution of use that these drugs would have in the hypothetical funded scenario is not known, but in the base case it was assumed that their distribution would be $44.6 \%$ for varenicline, $4.2 \%$ for bupropion, and 51.2\% for NRT. This distribution is justified by what has been observed in reference countries where these drugs receive some type of public funding, such as the Netherlands, Switzerland, or the United Kingdom, and by the different efficacy/safety ratios for such drugs observed in clinical trials with COPD patients.

\section{Population}

The cohort section of the model was used to identify the target population, consisting of COPD diagnosed patients, who would be willing to stop smoking and have tried at least once in the last year using a pharmacological aid.
The population used in the analysis was determined by using an epidemiological algorithm (Figure 1), and it included the Spanish population of smokers diagnosed with COPD, aged $\geq 40$ years (COPD defined according to the old European Respiratory Society guidelines as applied in two studies showing the prevalence of COPD in Spain). ${ }^{11,15}$ Because of the differences in use of resources and prevalence of smoking by age and sex, the population was stratified by sex in the following age groups: $40-69$ years and $\geq 70$ years. For the total Spanish population $\geq 40$ years $(24,321,996$ people as of January 1, 2013), ${ }^{16}$ the prevalence of COPD in Spain was used $\left(4.5 \%{ }^{15}\right.$ between the ages of 40 and 69 and $18.1 \%{ }^{10}$ for $\geq 70$ years). A COPD diagnosis rate of $27 \%{ }^{15}$ was used, as was a smoking prevalence in this population of $29.1 \%{ }^{15}$ in patients aged $40-69,12.2 \%$ in men $>70$ and $4.2 \%$ in women $>70 .{ }^{17}$ The EPISCAN study ${ }^{15}$ showed that $61 \%$ of patients with COPD who smoke would be ready to quit smoking, $42.8 \%$ of whom would have tried at least once to stop smoking in the past year, ${ }^{18}$ and $13.9 \%$ of these patients would use one of the available drugs. ${ }^{19}$ In addition to this prevalent population, a yearly incidence of new COPD cases of 15.6 per 1,000 men and 3.1 per 1,000 women was used, ${ }^{20}$ which was applied starting from the second year of analysis.

To calculate the population for the funded scenario based on smoking-cessation drugs plus counseling, an increase of $10 \%$ of the proportion of COPD patients diagnosed was used to find the potential effect of funding on diagnosis rate. In addition, it was considered that in a situation where the alternatives evaluated were funded, the proportion of patients who would be willing to stop smoking using one of these drugs would increase to $61.7 \%$, the same figure as that estimated from the survey carried out by the National Committee for the Prevention of Smoking. ${ }^{18}$

\section{Structure of the model}

The analysis starts with the target population described earlier, who would be treated with one of the smokingcessation alternatives plus counseling. The efficacy of the drug observed in COPD patients determines whether the treatment is successful or the patient relapses into smoking. A patient who stops smoking for a full year is considered a smoking-cessation success. The model provides for the possibility of further attempts with the same drug, up to a maximum of three, during a 5-year period starting from the first attempt to quit, ${ }^{21}$ both in case of failure after the initial attempt as well as in case of relapse after a successful attempt. Relapse was fitted at 3\% yearly rate after 52 weeks of abstinence. ${ }^{22}$ These situations represent the Markov-chain part of the hybrid model (Figure 1). 


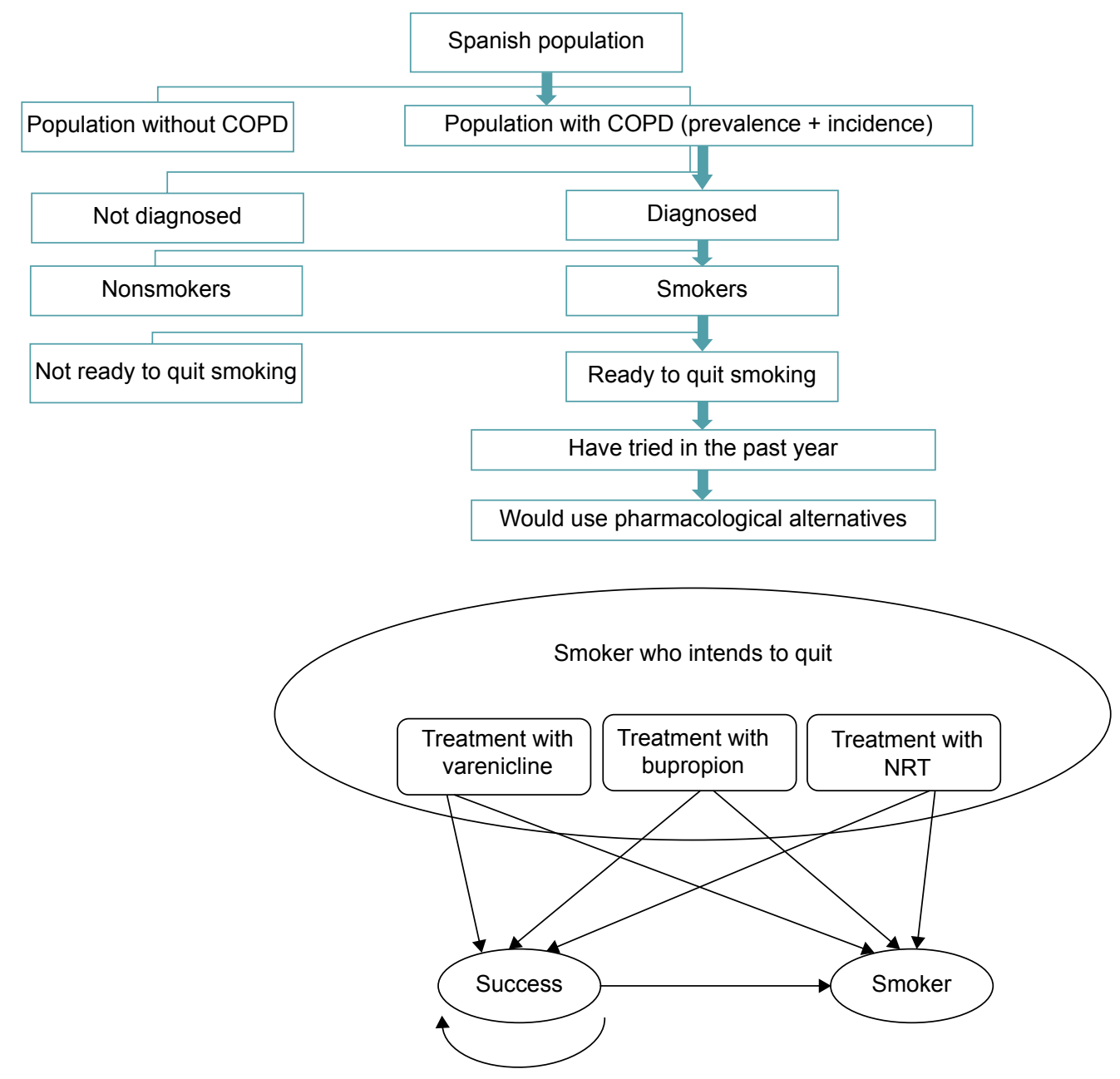

Figure I Diagram of the model: epidemiological cohort and Markov chain.

Abbreviations: COPD, chronic obstructive pulmonary disease; NRT, nicotine replacement therapy.

The efficacy of the drugs in COPD was expressed as the continuous abstinence rate after 52 weeks following the attempt to quit: $10.0 \%$ for bupropion, ${ }^{23} 18.6 \%$ for varenicline, ${ }^{24}$ and $14.0 \%$ for NRT. ${ }^{25}$ In the funded scenario, these figures were applied, considering that the funding is to be combined with medical follow-up and counseling similar to that followed in the clinical trial protocols. In routine clinical practice, lack of funding has been associated with a drop in medical follow-up and less antismoking counseling, which results in real-world effectiveness values lower than those observed in clinical trials. As such, in the unfunded scenario, the efficacy rates were corrected by using a deflator coefficient of $0.547 .{ }^{26}$

\section{Resources and costs}

The cost of the therapies in the funded scenario was calculated based on the current manufacturer selling price ${ }^{27,28}$ and by considering the dose, duration, and compliance for the 12 weeks of treatment (66\% for bupropion, ${ }^{23} 78 \%$ for
NRT, ${ }^{25}$ and $84 \%$ for varenicline $)^{24}$ observed in the clinical trials (Table 1). In the funded scenario, the attempts to stop smoking are associated with an increase of one initial visit with a specialist doctor and four visits with the nursing staff for each attempt. In the unfunded scenario, neither the pharmacological costs of the smoking-cessation treatments nor the health care costs of the medical visits with specialists and/or nursing staff are assigned.

The economic benefits stemming from avoiding the use of health care resources in patients who stop smoking were obtained from the literature and were calculated starting from the second year of cessation, based on the requirement of 12 months without smoking as the criterion for considering smoking abstinence. ${ }^{10}$ All costs (Table 1) are expressed in Euros ( $€, 2014$ values).

\section{Analysis}

For each scenario, the economic impact is calculated based on the estimated number of patients who effectively stop 
Table I Unit costs (in €, 20I4)

\begin{tabular}{|c|c|c|}
\hline Parameter & Cost (in $€, 2014$ ) & \\
\hline Smoking-cessation drugs & MSP-VAT ${ }^{\mathrm{a}, 27}$ & RRP-VAT ${ }^{\mathrm{a}, 27}$ \\
\hline \multicolumn{3}{|c|}{ Cost of treatment considering dose, duration, and compliance as observed in the clinical trials $\mathbf{s}^{33-35}$} \\
\hline Varenicline & $€ 159.30$ & $€ 248.67$ \\
\hline Bupropion & $€ 108.33$ & $€|69.1|$ \\
\hline Nicotine replacement therapy & $€ 152.50$ & $€ 238.06$ \\
\hline Medical visits & Unit cost $\mathrm{t}^{40,41}$ & \\
\hline Initial visit with specialist & $€ 130$ & \\
\hline Follow-up visit with specialist & $€ 78$ & \\
\hline Visit with nursing personnel & $€ 18$ & \\
\hline \multicolumn{3}{|c|}{ Yearly economic benefits in terms of health care resources avoided in patients who quit smoking by year of cessation ${ }^{\mathrm{b}, 10}$} \\
\hline & 40-69 years & $\geq 70$ years \\
\hline First year & $€ 0$ & $€ 0$ \\
\hline Second year & $€ 770$ (95\% Cl: 90-I,53I) & $€ \mathrm{I}, 398$ (95\% Cl: $96 \mathrm{I}-\mathrm{I}, 836)$ \\
\hline Third year & $€ \mathrm{I}, 089$ (95\% Cl: $36 \mathrm{I}-1,727)$ & $€ \mathrm{I}, 977$ (95\% Cl: I,34I-2,644) \\
\hline Fourth year & $€ \mathrm{I}, 567(95 \% \mathrm{Cl}: \mathrm{I}, 079-2,024)$ & $€ 2,258$ (95\% Cl: I,877-2,69I) \\
\hline Fifth year & $€ \mathrm{I}, 87 \mathrm{I}(95 \% \mathrm{Cl}: \mathrm{I}, 435-2,328)$ & $€ 2,356$ (95\% Cl: I,889-2,773) \\
\hline
\end{tabular}

Notes: aRequired deduction of $7.5 \%$ included as per RD $8 / 2010$. ${ }^{\circ}$ Avoided costs are referred to as COPD-specific drugs, oxygen therapy, primary care medical visits, specialist medical visit, and emergency visit, hospital admissions due to COPD exacerbations of cardiovascular events, diagnostic procedures, and laboratory tests.

Abbreviations: Cl, confidence interval; COPD, chronic obstructive pulmonary disease; MSP-VAT, manufacturing selling price-value added tax; RD, Royal decree; RRP-VAT, recommended retailing price-value added tax.

smoking in each year, multiplied by the average yearly health care costs avoided due to stopping smoking that accumulate starting from the second year the patient stops smoking and are added during the complete follow-up period of 5 years of analysis.

\section{Sensitivity analysis}

To test the model robustness, alternative scenarios were performed by changing case (each time modifying one assumption of the model) of the premises and values of the parameters with greater uncertainty. In all, twelve alternative analyses were performed, with the following characteristics: use of an annual discount rate of $3 \%,{ }^{12}$ increase of $25 \%$ in the COPD diagnosis rate up to $33.75 \%$; duplication of the yearly relapse rate up to $6.3 \%,{ }^{29}$ increase of $50 \%$ of patients who want and try to stop smoking as a result of funding; proportion of use of smoking-cessation drugs in the funded scenario equal to that used in the unfunded scenario; efficacy of the smoking-cessation drugs equal to that seen in addictive behavior units (varenicline, 57.4\%; bupropion, 52.9\%; and NRT, 47.1\%); ${ }^{14}$ alternative efficacy of smoking-cessation drugs (varenicline, 33.2\%; bupropion, 24.2\%; and NRT, $26.3 \%$ ) based on a Cochrane review; ${ }^{3}$ efficacy of smokingcessation drugs equal to that seen in tobacco-cessation units (varenicline, 43.0\%; bupropion, 46.2\%; and NRT, $28.7 \%) ;{ }^{30}$ economic benefit of costs avoided in patients who stop smoking, with a value equal to the lower limit of the $95 \%$ confidence interval instead of the mean value of cost avoided; ${ }^{10}$ copayment of $0 \%$ by patients of the cost of the smoking-cessation drugs, given as total funding by the NHS of the recommended retail price plus value added tax (VAT) of the drugs instead of the manufacturer selling price used for the base-case scenario; copayment of $50 \%$ by patients based on the model used in the Autonomous Community of the Canary Islands for funding in patients with respiratory diseases; and increase in medical health care visits in the funded scenario, resulting in an initial visit with the specialist, a follow-up visit with the specialist, and four visits with the nursing staff for each attempt to quit.

\section{Results}

It was estimated that, in the unfunded scenario, the cohort of COPD patients willing to quit with a drug would be 3,638 ; 3,905; 4,167; 4,426; and 2,006 patients in the first, second, third, fourth, and fifth years, respectively, for an accumulated total of 18,142 patients, 1,303 of whom would stop smoking during the analyzed period. In the funded scenario, the patient cohort was estimated to be 26,740 in the first year, 26,579 in the second year, 26,630 in the third year, 26,850 in the fourth year, and 13,361 in the fifth year, for an accumulated total of 120,161 smokers, 17,756 of whom would stop smoking. Table 2 shows the breakdown of the calculation of the number of patients in each scenario. In the unfunded scenario, neither costs associated with smoking-cessation drugs nor health care costs that had to be paid by the NHS were considered. The funded scenario would involve an accumulated investment 


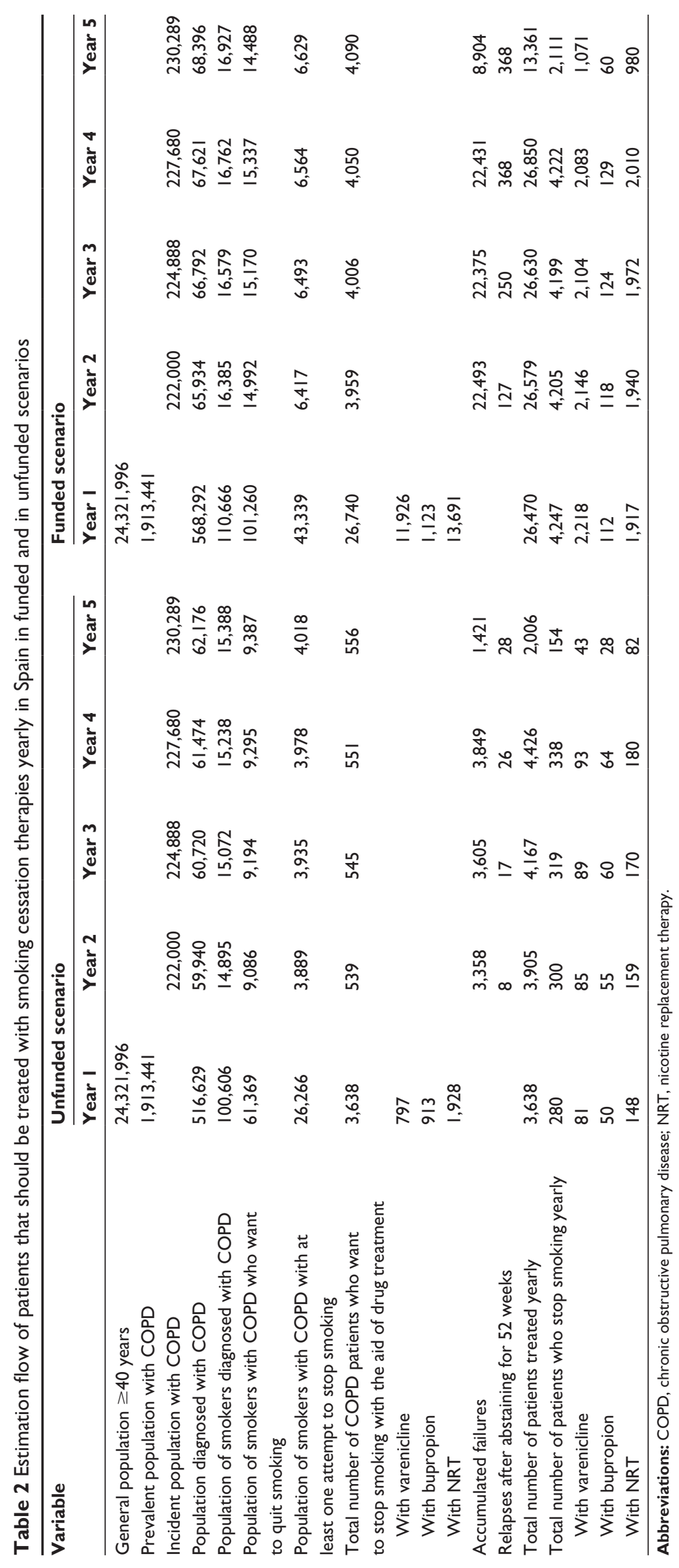


during the 5-year analysis of $€ 18,436,000$, corresponding to the cost of smoking-cessation drugs, plus $€ 21,914,000$, that are due to medical visits (specialist and nursing staff), which would amount to a total cost of $€ 40,350,000$ over the 5 years.

The savings due to smoking cessation (observable starting from the second year of quitting) in the unfunded scenario were estimated to be $€ 270,000$ for the second year, $€ 653,000$ for the third year, $€ 1,145,000$ for the fourth year, and $€ 1,316,000$ for the fifth year. In the funded scenario, these savings would be, $€ 4,096,000$, $€ 9,573,000, € 16,319,000$, respectively, and $€ 18,005,000$ in the last year (Table 3 ). The budgetary impact of funding the smoking-cessation drugs would result in a cost difference of $+€ 9,038,000$ in the first year, $+€ 5,115,000$ in the second year, $+€ 708,000$ in the third year, $-€ 6,212,000$ in the fourth year, and $-€ 12,201,000$ in the fifth year, which produces accumulated savings during the 5-year analysis of $€ 4,258,000$ (Table 3 ). Table 4 shows the budgetary impact split by the various autonomous communities.

In the sensitivity analysis, the efficacy of the smokingcessation therapies was observed to be the parameter with the greatest influence on the results (Figure 2). In the analysis where the efficacy observed in addictive behavior units was applied, the accumulated impact during the 5-year period for the funded scenario, compared with the unfunded scenario, reached a maximum value of $€ 89,880,000$ in savings for the NHS. By contrast, when the value below the $95 \%$ confidence interval of the economic benefits associated with smoking cessation is considered, an accumulated impact over 5 years would amount to $€ 18,371,000$. The tornado chart shown in Figure 3 gives the results of the accumulated impact over the 5 years derived from modifying the parameters used in the sensitivity analyses.

\section{Discussion}

A BIA is intended to provide data on the effect of adding new health care technologies and medicines to the public budgets, both in aggregated form for the NHS as a whole as well as for the regional health services. Though not intended to replace the use of other types of economic evaluations, this type of study fulfils the important objective of providing decision-makers with relevant data on the financial viability of adopting new treatments. ${ }^{31}$ With the potential funding of drug treatments to aid smoking cessation, the efficacy of which has been clearly shown in the literature, ${ }^{9,32-35}$ the BIA of including these drugs in the public funds for medicinal products offers guidance for the potential increase in pharmaceutical spending, an aspect with increasing significance nowadays.

This study included a BIA of funding treatment to help smokers with COPD in Spain quit smoking. A 5-year hybrid model was designed that provides for NHS funding together with a normal copayment by patients. The data show that in the current unfunded scenario, a total of only 1,303 smokers with COPD would stop smoking over the 5 years; whereas, in the funded scenario, this would increase to a total of 17,756 . This would amount to a total estimated extra savings for the NHS of $€ 4,258,000$ as a result of funding. It should also be noted that the single-variable sensitivity analysis indicates that both the large-scale incorporation of smokers with COPD into the program with funded treatment, as well as the increased effectiveness of the treatments provided, would augment the economic benefits for the NHS.

The vast majority of scientific health care institutions recommend that public health services fund smoking-cessation treatments, ${ }^{3,36}$ as they are considered to be one of the most effective health care interventions. ${ }^{3}$ In addition, it must be noted that the only treatment that has proved to be effective in stopping COPD from progressing in patients who smoke is quitting smoking, and the COPD treatments currently available, apart from being expensive, are only symptomatic and are not able to stop the disease from progressing. ${ }^{37}$ These reasons seem to favor funding for smoking-cessation

Table 3 Results of the budget-impact analysis for the Spanish National Health System, by year and accumulated cost

\begin{tabular}{|c|c|c|c|c|c|c|c|}
\hline Variable & & Year I & Year 2 & Year 3 & Year 4 & Year 5 & Accumulated \\
\hline \multirow[t]{2}{*}{ Cost in smoking-cessation drugs (in millions of $€$ ) } & Without funding & 0 & 0 & 0 & 0 & 0 & 0 \\
\hline & With funding & 4.109 & 4.080 & 4.083 & 4.114 & 2.500 & 18.436 \\
\hline \multirow[t]{2}{*}{ Health care costs (in millions of $€$ ) } & Without funding & 0 & 0 & 0 & 0 & 0 & 0 \\
\hline & With funding & 4.929 & $4.86 \mathrm{I}$ & 4.838 & 4.848 & 2.438 & 21.914 \\
\hline \multirow[t]{2}{*}{ Mean costs incurred (in millions of $€$ ) } & Without funding & 0 & 0 & 0 & 0 & 0 & 0 \\
\hline & With funding & 9.038 & 8.941 & 8.921 & 8.962 & 4.488 & 40.350 \\
\hline \multirow[t]{2}{*}{ Mean costs avoided by stopping smoking (in millions, $€$ ) } & Without funding & 0 & 270 & 653 & 1.145 & 1.316 & 3.384 \\
\hline & With funding & 0 & 4.096 & 9.573 & 16.319 & 18.005 & 47.992 \\
\hline $\begin{array}{l}\text { Budgetary impact (in millions, } € \text { ) for National Health System } \\
\text { due to effect of funding vs no funding }\end{array}$ & & 9.038 & 5.115 & 708 & -6.212 & -12.201 & -4.258 \\
\hline
\end{tabular}


Table 4 Results of the budget-impact analysis (in millions of $€$ ), by year and accumulated cost, in the autonomous community-funded scenario with smoking-cessation drugs

\begin{tabular}{lllllll}
\hline Autonomous community & Year I & Year 2 & Year 3 & Year 4 & Year 5 & Accumulated \\
\hline Andalusia & 1.531 & 866 & 120 & -1.052 & -2.067 & -721 \\
Aragon & 273 & 154 & 21 & -187 & -368 & -128 \\
Asturias & 241 & 136 & 19 & -165 & -325 & -113 \\
Balearic Islands & 201 & 114 & 16 & -138 & -272 & -95 \\
Cantabria & 122 & 69 & 10 & -84 & -165 & -58 \\
Canary Islands & 393 & 222 & 31 & -270 & -530 & -185 \\
Castilla-La Mancha & 393 & 222 & 31 & -270 & -530 & -185 \\
Castile and León & 551 & 312 & 43 & -379 & -744 & -260 \\
Catalonia & 1.428 & 808 & 112 & -982 & -1.928 & -673 \\
Ceuta and Melilla & 25 & 14 & 2 & -17 & -35 & -12 \\
Extremadura & 218 & 123 & 17 & -150 & -295 & -103 \\
Galicia & 597 & 338 & 47 & -410 & -806 & $-28 I$ \\
Madrid & 1.197 & 678 & 94 & -823 & -1.616 & -564 \\
Murcia & 254 & 144 & 20 & -175 & -343 & -120 \\
Navarre & 125 & 71 & 10 & -86 & -169 & -59 \\
Basque country & 460 & 260 & 36 & -316 & -621 & -217 \\
La Rioja & 63 & 36 & 5 & -44 & -86 & -30 \\
Valencia & 964 & 546 & 76 & -663 & -1.302 & -454 \\
\hline
\end{tabular}

treatments in smokers with COPD. In Spain, a country suffering a serious economic crisis and where there is public funding for medicines, the political and health authorities fund every kind of COPD treatment except smoking-cessation treatment in these patients.

An interesting conclusion, based on the results of this study, is that profits for the NHS and the public health services in the various autonomous communities of Spain would become evident from the fourth year of funding, which would make investing in smoking-cessation treatment in smokers with COPD a short-term investment. This finding has been greatly valued by those making decisions on health care policies. ${ }^{38,39}$ Furthermore, another important finding was that funding smoking-cessation therapies, not only lead to a higher number of patients willing to quit smoking with the aid of combined therapies, but would generate even more savings for the public health service. The higher number of smokers who would be willing to quit smoking by using the funded

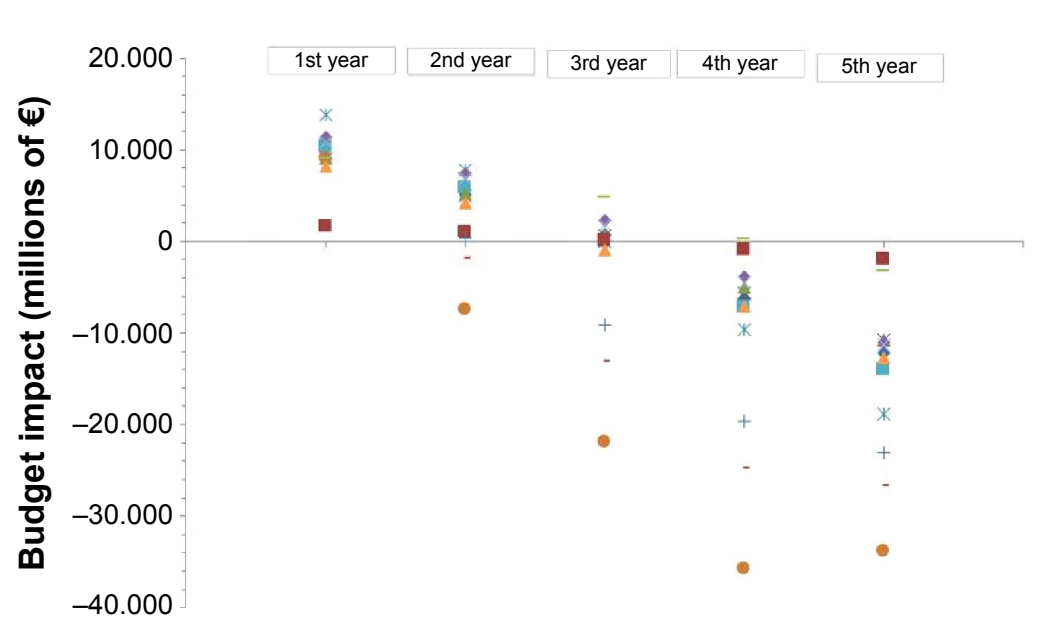

- Base case

With yearly discount rate $(3 \%)$

- Increment of $25 \%$ in COPD diagnosis rate

A Double the relapse rate $(6.3 \%)$

* Increment of $50 \%$ of patients who want and try to stop smoking

- Percentage of use of funded drugs equivalent to unfunded

- Drug efficacy seen in specialist addictive units

+ Drug efficacy according to Cochrane review

- Drug efficacy seen in tobacco detoxification units

$=$ Lower limit of the $95 \%$ confidence interval of avoided costs due to stopping smoking

- Drug copayment by patients of $0 \%$

$\Delta$ Drug copayment by patients of $50 \%$

Increase in health care visits (follow-up specialist additional visit)

Figure 2 Results of the budget impact for the sensitivity analysis.

Notes: The values (in millions of $€$ ) of the different scenarios show the impact of the current funded scenario compared with the current unfunded scenario. BIA, budgetimpact analysis. The values (in millions of $€$ ) of the different scenarios show the impact of this scenario on the current unfunded scenario after discarding the value observed in the current scenario.

Abbreviation: COPD, chronic obstructive pulmonary disease. 


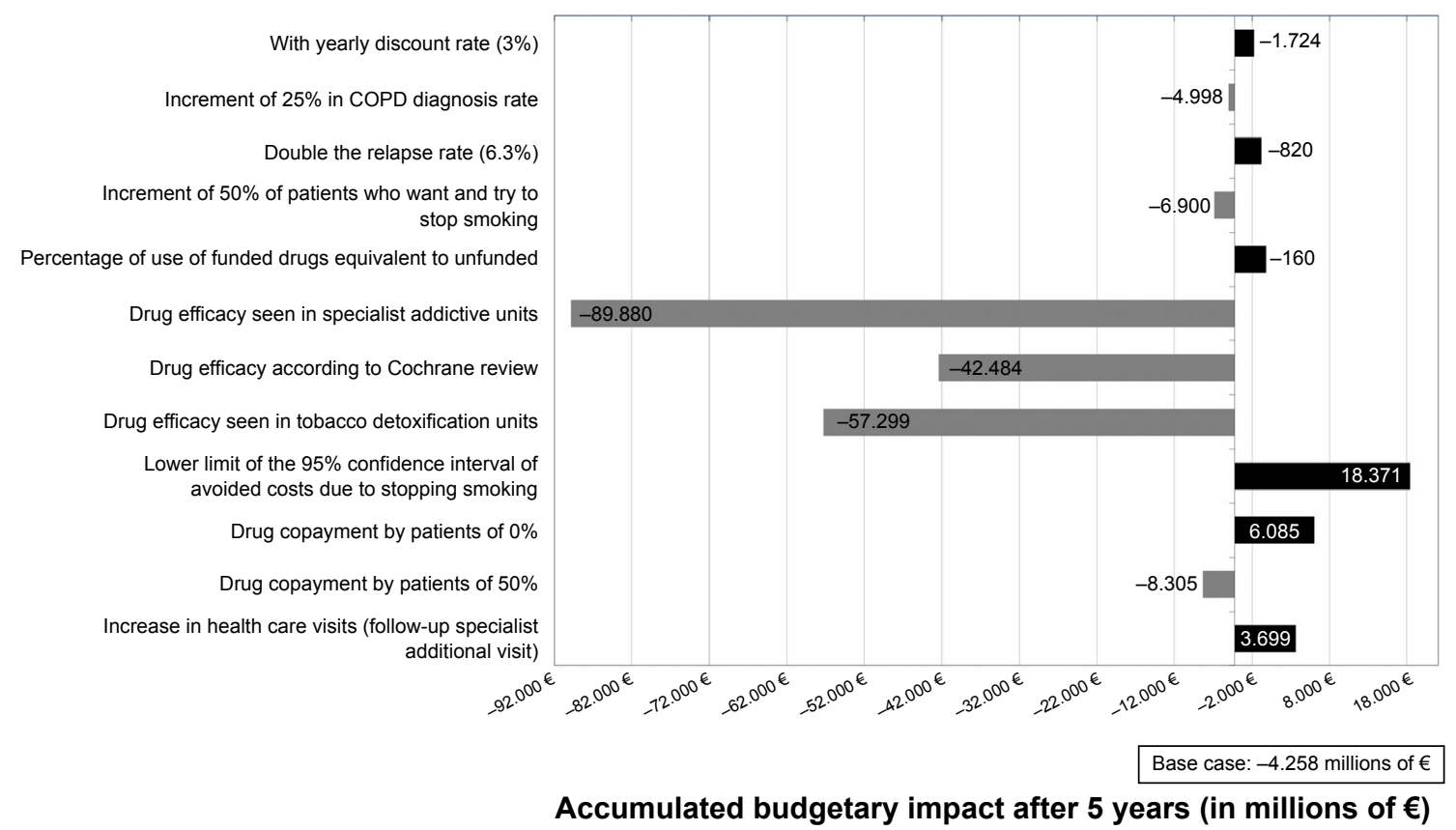

Figure 3 Tornado chart showing the results of the accumulated budgetary impact after the 5-year sensitivity analysis. Note: The values (in millions of $€$ ) indicate the differences between the funded and unfunded scenarios.

Abbreviation: COPD, chronic obstructive pulmonary disease.

treatments has been one of the problems noted by health care administrators faced with deciding whether to approve funding, for fear that such an increase would lead to higher health care costs. ${ }^{38,39}$ The hypothetical increase of $50 \%$ of subjects, who would be willing to make a serious attempt to quit smoking with the aid of combined treatment, would generate additional savings of $€ 6,900,000$ after 5 years. On the other hand, increasing effectiveness of these drugs in smokers with COPD would result in a significant increase in economic benefits for the NHS. The data suggest that, if all smokers with COPD were managed in tobacco units staffed with experts in this area, the savings for the NHS would amount to $>€ 45,000,000$ after 5 years.

This analysis does have some possible constraints that should be considered when interpreting the results. The first is due to the particularly short period of modeling used for an intervention, the clinical benefits of which are observed over the long term and, therefore, the actual long-term savings from success in smoking cessation could be underestimated. The 5-year period, however, is sufficient for observing drug effectiveness after several attempts and is therefore a realistic approximation of what happens in clinical practice. The model does not consider periods of treatment with smokingcessation drugs of less or more than the 12 weeks contained in most clinical trials with these drugs. The analysis assumes that all smoking-cessation attempts will be made using the same drug, because no information is available on effectiveness in patients who switch to a different pharmacological alternative. The possibility of cessation attempts using two or more drugs at the same time was also not analyzed because although this combination may succeed in some cases in routine clinical practice, it is not recommended in the summaries of product characteristics of these drugs. Although smoking-cessation drugs may have adverse effects, any cost these might have is not included in the analysis because the impact would be associated more with quitting and treatment failure than with a relevant use of resources to manage such an impact. This analysis does not include estimated mortality rates in smokers in the model in the prevalent cases who failed and tried again to quit smoking, because it was assumed that in the 5 years of modeling, the estimated number of deaths would be very low and would not substantially change the results. In line with the chosen perspective, the effect on absenteeism in the workplace was not considered. Finally, we developed a mathematical model trying to predict the human behavior, which needed the incorporation of several assumptions, which were also managed in a sensitivity analysis; inherent limitations could not be completely ruled out.

The results of this analysis indicate that smoking cessation with the aid of pharmacological alternatives generates economic benefits for the NHS due to patients who quit smoking. Public funding for these drugs would involve long-term savings for the NHS, savings, which were evident from the fourth year of analysis. The estimated economic 
benefits increased proportionally with the increase in the population able to take part in a program that funds smoking cessation, with a parallel increase in the effectiveness of these drugs stemming from better follow-up by the medical staff involved in the antismoking counseling. In conclusion, funding smoking-cessation drugs is a public health strategy that is economically beneficial for Spain's NHS.

\section{Acknowledgments}

The budget-impact model was developed by Carlos Collados from Trial FormSupply, Spain, and Javier Rejas from Pfizer, SLU, and was funded by Pfizer, SLU.

\section{Disclosure}

I Oyagüez is employed by Pharmacoeconomics \& Outcomes Research Iberia, a company specializing in economic evaluations of health care interventions, which received unconditional funding from Pfizer to develop and write this manuscript. The authors declare no other conflicts of interest with this work.

\section{References}

1. World Health Organization. Geneva; 2014. Available from: http://www who.int/tobacco/health_priority/en/index.html. Accessed July 21, 2014.

2. Banegas JR, Díez-Gañán L, Bañuelos-Marco B, etal. Smoking-attributable deaths in Spain, 2006. Med Clin (Barc). 2011;136:97-102.

3. Fiore MC, Jaén CR, Baker TB. Treating Tobacco Use and Dependence: 2008 Update. Clinical Practice Guideline; 2013. Rockville, MD: U.S. Department of Health and Human Services. Public Health Service. Available from: http://www.ncbi.nlm.nih.gov/books/NBK63952/. Accessed September 27, 2013.

4. Rennard SI, Daughton DM. Smoking cessation. Clin Chest Med. 2014;35:165-176.

5. Rigotti NA. Smoking cessation in patients with respiratory disease: existing treatments and future directions. Lancet Respir Med. 2013;1:241-250.

6. Lock K, Wilson K, Murphy D, Riesco JA. A cost-effectiveness model of smoking cessation based on a randomized controlled trial of varenicline versus placebo in patients with chronic obstructive pulmonary disease. Expert Opin Pharmacother. 2011;12:2613-2626.

7. Jiménez-Ruiz CA, Riesco Miranda JA, Altet Gómez N, et al; Sociedad Española de Neumología y Cirugía Torácica (SEPAR). Treatment of smoking in smokers with chronic obstructive pulmonary disease. Sociedad Española de Neumología y Cirugía Torácica (SEPAR). Arch Bronconeumol. 2013;49:354-363.

8. SEMERGEN. Consenso para la prevención y terapia de la enfermedad tabáquica [Consensus for prevention and therapy of smoking]; 2007. Available from: http://www.semergen.es. Accessed June 26, 2014.

9. González-Enríquez J, Salvador-Llivina T, López-Nicolás A, et al. The effects of implementing a smoking cessation intervention in Spain on morbidity, mortality and health care costs. Gac Sanit. 2002;16:308-317.

10. Sicras-Mainar A, Rejas-Gutiérrez J, Navarro-Artieda R, Ibañez-Nolla J. The effect of quitting smoking on costs and healthcare utilization in patients with chronic obstructive pulmonary disease: a comparison of current smokers versus ex-smokers in routine clinical practice. Lung. 2014;192:505-518.

11. Jiménez-Ruiz CA, Riesco Miranda JA, Ramos Pinedo A, et al. Recommendations for pharmacological tobacco cessation treatments: proposals for financing. Arch Bronconeumol. 2008;44:213-219.
12. López-Bastida J, Oliva J, Antoñanzas F, et al. Spanish recommendations on economic evaluation of health technologies. Eur J Health Econ. 2010;11:513-520.

13. Sullivan SD, Mauskopf JA, Augustovski F, et al. Budget impact analysis-principles of good practice: report of the ISPOR 2012 Budget Impact Analysis Good Practice II Task Force. Value Health. 2014;17: 5-14.

14. Sicras-Mainar A, Navarro Artieda R, Díaz Cerezo S, Martí-Sanchéz B, Sanz De Burgoa V. Abstinence rates with varenicline compared to bupropion and nicotine replacement therapy for quitting smoking in primary care. Aten Primaria. 2011;43:482-489.

15. Soriano JB, Ancochea J, Miravitlles M, et al. Recent trends in COPD prevalence in Spain: a repeated cross-sectional survey 1997-2007. Eur Respir J. 2010;36:758-765.

16. National Institute of Statistics (INE) of Spain. Proyecciones de la población española for 2013 [Spanish population projections for 2013]; 2013. Available from: http://www.ine.es. Accessed September 27, 2013.

17. de Miguel Diez J, Carrasco Garrido P, García Carballo M, et al. Determinants and predictors of the cost of COPD in primary care: a Spanish perspective. Int J Chron Obstruct Pulmon Dis. 2008;3:701-712.

18. Comité Nacional para la Prevención del Tabaquismo; 2008 [National Committee for Prevention of smoking: 2008]. Available from: http:// www.cnpt.es/listado-recursos.asp?id_categoria=23\&id_subcategoria=1\&pagina=8. Accessed September 27, 2013.

19. Jiménez Ruiz CA, Fernando Masa J, Sobradillo V, et al. Prevalence of and attitudes towards smoking in a population over 40 years of age. Arch Bronconeumol. 2000;36:241-244.

20. de Lucas Ramos P, Álvaro Alvarez D. Actualizaciones en la EPOC 2010 [Update for COPD 2010]. Monografías NEUMOMADRID, Vol. XV; 2010. Available from: http://www.neumomadrid.org/descargas/monog_neumomadrid_xv.pdf. Accessed September 27, 2013.

21. Getsios D, Marton JP, Revankar N, et al. Smoking cessation treatment and outcomes patterns simulation: a new framework for evaluating the potential health and economic impact of smoking cessation interventions. Pharmacoeconomics. 2013;31:767-780.

22. Krall EA, Garvey AJ, Garcia RI. Smoking relapses after 2 years of abstinence: findings from the VA Normative Aging Study. Nicotine Tob Res. 2002;4:95-100.

23. Tashkin D, Kanner R, Bailey W, et al. Smoking cessation in patients with chronic obstructive pulmonary disease: a double-blind, placebocontrolled, randomized trial. Lancet. 2001;357:1571-1575.

24. Tashkin DP, Rennard S, Hays JT, Ma W, Lawrence D, Lee TC. Effects of varenicline on smoking cessation in patients with mild to moderate COPD: a randomized controlled trial. Chest. 2011;139:591-599.

25. Tønnesen P, Mikkelsen K, Bremann L. Nurse-conducted smoking cessation in patients with COPD using nicotine sublingual tablets and behavioral support. Chest. 2006;130:334-342.

26. Zhu SH, Anderson CM, Tedeschi GJ, et al. Evidence of real-world effectiveness of a telephone quit line for smokers. N Engl J Med. 2002; 347:1087-1093.

27. Drug Catalogue of the Consejo General de Colegios de Farmacéuticos. Bot Plus Web; 2013 [Drug Catalogue of the General Council of Official Colleges of Pharmacists]. Available from: http://www.portalfarma.com. Accessed September 27, 2013.

28. Royal Decree-Law (RD). Real Decreto-ley 8/2010, de 20 de mayo, por el que se adoptan medidas extraordinarias para la reducción del déficit público. BOE [Spain's Official Government Gazette] de 24 de Mayo 2010:126;2010. Available from: www.boe.es/boe/dias/2010/05/24/ pdfs/BOE-A-2010-8228.pdf. Accessed June 25, 2014.

29. Wetter DW, Cofta-Gunn L, Fouladi RT, Cinciripini PM, Sui D, Gritz ER. Late relapse/sustained abstinence among former smokers: a longitudinal study. Prev Med. 2004;39:1156-1163.

30. Jiménez Ruiz CA, Ramos Pinedo A, Cicero Guerrero A, Mayayo Ulibarri M, Cristobal Fernández M, Lopez Gonzalez G. Characteristics of COPD smokers and effectiveness and safety of smoking cessation medications. Nicotine Tob Res. 2012;14:1035-1039. 
31. Brosa M, Gisbert R, Rodríguez JM, Soto J. Principios, métodos y aplicaciones del análisis del impacto presupuestario en el sector sanitario [Principles, methods and applications for budgetary impact analysis for health interventions]. Pharmacoecon Span Res Artic. 2005;2:64-78.

32. Cornuz J, Gilbert A, Pinget C, et al. Cost-effectiveness of pharmacotherapies for nicotine dependence in primary care settings: a multinational comparison. Tob Control. 2006;15:152-159.

33. Song F, Raftery J, Aveyard P, Hyde C, Barton P, Woolacott N. Costeffectiveness of pharmacological interventions for smoking cessation: a literature review and a decision analytic analysis. Med Decis Making. 2002;22(5 suppl):S26-S37.

34. Fernández de Bobadilla Osorio J, Sánchez-Maestre C, BrosaRiestra M, Arroyo O, Sanz De Burgoa V, Wilson K. Cost effectiveness analysis of varenicline (Champix) for the treatment of smoking in Spain. An Med Interna. 2008;25:342-348.

35. Antoñanzas F, Portillo F. Evaluación económica del empleo de terapias farmacológicas para la cesación en el hábito tabáquico [Economic evaluation of pharmacotherapies for smoking cessation]. Gac Sanit. 2003; 17:393-403.

36. de Granda JI, Carrión F, Alonso S, et al; Area de Tabaquismo de la SEPAR. Tobacco addiction: care and services. Arch Bronconeumol. 2006; 42:600-604
37. Global Strategy for the Diagnosis, Management and Prevention of COPD. Global Initiative for Chronic Obstructive Lung Disease; 2010. Available from: http://www.goldcopd.org/. Accessed September 2013.

38. Menzin J, Lines LM, Marton J. Estimating the short-term clinical and economic benefits of smoking cessation: do we have it right? Expert Rev Pharmacoecon Outcomes Res. 2009;9:257-264.

39. Warner KE, Mendez D, Smith DG. The financial implications of coverage of smoking cessation treatment by managed care organizations. Inquiry. 2004;41:57-69.

40. Tarifas de asistencia sanitaria ambulatoria de la Comunidad de Madrid (B.O.C.M. 215 de 10 de septiembre de 2013) [Tariffs of healthy outpatient resources of Autonomous Community of Madrid]; 2013. Available from: http://w3.bocm.es/boletin/CM_Orden_BOCM/2013/09/10/ BOCM-20130910-1.PDF. Accessed September 27, 2013.

41. Guía de deshabituación tabáquica del Instituto Catalán de la Salud; 2013 [Guideline for smoking cessation of the Catalonia Institute of Health]. Available from: http://www.ics.gencat.cat $/ 3 \mathrm{clics} / \mathrm{main} . \mathrm{php}$ ?page= GuiaPage\&idGuia=1\&lang=CAS. Accessed September 27, 2013.
International Journal of COPD

\section{Publish your work in this journal}

The International Journal of COPD is an international, peer-reviewed journal of therapeutics and pharmacology focusing on concise rapid reporting of clinical studies and reviews in COPD. Special focus is given to the pathophysiological processes underlying the disease, intervention programs, patient focused education, and self management protocols.

\section{Dovepress}

This journal is indexed on PubMed Central, MedLine and CAS. The manuscript management system is completely online and includes a very quick and fair peer-review system, which is all easy to use. Visit http://www.dovepress.com/testimonials.php to read real quotes from published authors. 